Kitara et al., Afr. J. Infect. Dis. (2013) 7(2): 36 - 43

http://dx.doi.org/10.4314/ajid.v7i2.4

\title{
ASSERTIVENESS AND ATTITUDES OF HIV/AIDS ORPHANED GIRLS TOWARDS EDUCATION IN KAMPALA (UGANDA).
}

\author{
${ }^{* 1}$ David Lagoro Kitara, ${ }^{1}$ Hellen Christine Amongin, ${ }^{2}$ Joseph C Oonyu, ${ }^{2}$ Peter K Baguma \\ ${ }^{* 1}$ Gulu University, Faculty of Medicine, Department of Surgery, P.0. Box 166, Gulu, Uganda. \\ ${ }^{1}$ Gulu University, Faculty of Education and Humanity, Department of Psychology, P.0. Box 166, Gulu. \\ ${ }^{2}$ Institute of Psychology, Makerere University, School of Education, P.0. Box 7062 Kampala. \\ *E-mail: klagoro@gmail.com
}

\begin{abstract}
Whereas HIV/AIDS prevalence has been declining in Uganda from $30 \%$ to less than $10 \%$ in the last 2 decades, the number of HIV/AIDS orphaned girls in secondary schools is still high and girl children have tended to carry the heaviest burdens of family responsibilities thereby adversely affecting their assertiveness and attitudes towards education. Assertiveness is a critical life skill that enables a person to state an opinion, claim a right, or establish authority and it is important to improve attitude towards education. This study examined the relationship between assertiveness and attitude towards education of HIV/AIDS orphaned and non-orphaned adolescent school girls in Kampala. The California Psychological Inventory (CPI) Dominance (Do) Assertiveness Scale and the Attitude Scale were administered to 225 students consecutively selected from 6 secondary schools in Kampala. HIV/AIDS Orphaned girls had lower levels of assertiveness and most had a negative attitude towards education compared to non-orphaned girls. Girls orphaned to HIV/AIDS were less assertive compared to those orphaned by other causes. There was a positive relationship between assertiveness and attitude towards education among orphaned adolescent secondary school girls in Kampala. Girls orphaned to HIV/AIDS were less assertive compared to other school girls and have a poor attitude towards education.
\end{abstract}

Key words: HIV/AIDS, Orphans, adolescent girls, Assertiveness, secondary education, Kampala, Uganda.

\section{Introduction}

One of the greatest negative effects of HIV/AIDS infection in African families has been to the life and formal education of the girl child (Baggaley \& Needham, 1997). Girl children have been the main source of healthcare and livelihood for most African families (Baggaley \& Needham, 1997). This has even been made worst in families affected, inflicted by HIV/AIDS in which one or both of the parents were involved (Baggaley \& Needham, 1997). The cares for the sick parents always made the girl child miss school and also develop emotional stress making them present with inappropriate behaviours (Baggaley \& Needham, 1997). In the event of death of the parents due to the disease, most girl children suffer from the vacuum left by their parents (Foster, 2000). They had to take care of their other siblings and handle all their home chores (Foster, 2000). The extended family safety nets in Africa have been adversely weakened by this disease (Foster, 2000).

Assertiveness is a life skill which is a social competence used to cope in this case with academics, to meet fundamental challenges of forming stable human relationships and maintaining hope about the future, among other things (Opolot et al, 1997). Assertiveness is defined as politely refusing unreasonable requests or threats, standing for one's rights and needs without undue fear or anxiety and matching body posture to mood (Guez \& Allen, 1998). Observation shows that non orphaned adolescent secondary school girls were more assertive and have a more positive attitude towards formal education compared to orphaned girls (Opolot et al, 1997). Gunther et al. (1998), found that loss of a parent was one of the most tragic and stressful events in a child's life. Instead of detaching from the loved ones and resolving the loss, there was a greater attachment to the deceased parent thus creating in their minds the denial of the finality of death (Gunther et al, 1998).

For adolescent that had lost parents to HIV/AIDS, the grieving process was shrouded in stigmatization, secrecy and shame (Kitara et al, 2011). They experienced a double abandonment, one from the parent and the other from a society that shunned them for being associated with HIV/AIDS (Kitara et al, 2011). These negative factors drove HIV/AIDS orphaned teenagers underground as their coping capacities were stretched to the limits (Gunther et al., 1998). They had to maintain the precarious balance of continuing the normal daily life while acknowledging that their parents were lost forever (Gunther et al., 1998). The stigma attached to HIV/AIDS makes the situation worse for girls orphaned to HIV/AIDS (Kitara et al, 2011; Opolot et $a l, 1997)$. Formal education in this study was defined as a form of learning in which knowledge, skills, and habits of a group of 
http://dx.doi.org/10.4314/ajid.v7i2.4

people are transferred from one generation to the next through teaching, training, and research particularly from teachers. While, Attitude to education was defined as a settled way of thinking or feeling of a person thus, reflecting a person's behavior.

The purpose of the study was to examine and compare the relationship between assertiveness and attitude of secondary school girls towards education for girls orphaned to HIV/AIDS, girls orphaned by other causes and non orphaned girls.

\section{Subjects and Methods Study design}

A cross-sectional study was conducted between June and October 2005.

\section{Study site}

This study was conducted in six secondary schools within four of five divisions of Kampala city, Uganda. The schools were selected by a simple random sampling from a list of secondary schools from each of the divisions of Kampala city. On average, three secondary schools were found eligible in each of the divisions of the city and these three schools were subjected to a random sample by picking a ballot from a basket as we selected a school to be studied per division. For the remaining two schools, all the ballots that were not previously picked were returned to the same basket and mixed together and the first two ballots picked consecutively by the researcher were considered part of the study population.

\section{Study Population}

Six secondary schools were selected for the study, which involved 225 students: 75 students from each of the following three strata: Girls orphaned to HIV/AIDS, girls orphaned by other causes and non-orphaned girls. In each of five government schools, thirteen non-orphaned girls were sampled and recruited and in one of the schools, ten girls were selected for the study. All the orphaned girls were selected consecutively in given school to obtain the sample size.

\section{Study instruments}

Questionnaire was the main tool for data collection. The questionnaire had two parts: The California Psychological Inventory (CPI) Dominance (DO) Assertiveness Scale and the researcher constructed Attitude Scale. These two standard scales were modified to suit this particular study. Four undergraduate students from Makerere University were recruited as research assistants and were trained by the investigators before undertaking the research.

\section{Data collection procedure}

Before the questionnaire was administered to the selected schools, a pilot study was conducted in one secondary school that was not part of research site. Thereafter, modifications were then made to the questionnaire until it was considered sufficient to answer the objectives of this study.

\section{Ethical consideration}

Assent was obtained from each student, and confidentiality was ensured throughout the study. Ethical approval of the study was obtained from the Uganda National council of Science and Technology (UNCS\&T).

\section{Data analysis}

Statistical Package SPSS version 12.0 was used to analyze the data. Assertiveness and attitude of school girls towards education among orphaned and non-orphaned girls were computed. Descriptive statistics including means and standard deviations were obtained for these variables. A student's t-test at $\mathrm{p}<0.05$ level of significance was used for comparison of variables. Pearson product moment correlation coefficient was used to determine the relationships, the direction and magnitude of assertiveness and attitude towards education. ANOVA was used to establish the differences between the groups in their assertiveness and attitude towards education. Logistic Regression analysis was used to establish the effect of both assertiveness and attitude towards education. The California Psychological Inventory (CPI) Dominance (DO) Assertiveness Scale (modified). The scale had a reported reliability coefficient of Cranbach's alpha 0.80, but this time the reliability coefficient (Cranbach's Alpha) was 0.71 and a validity of 1.00. It had thirty six items on a Likert-type scale requiring responses of 'True' or 'False'.

The Attitude Scale (modified): The researcher's constructed scale had a reliability coefficient (Cranbach's Alpha) of 0.86 and a validity of 0.50 . It had forty eight items divided into four sections. Each section had twelve items. The sections included: (A) Attitude towards peers, (B) Attitude towards subjects in class; (C) Attitude towards teachers, and (D) Attitude towards facilities in the school. The items were in a Likert-type set up requiring responses of Strongly Agree (SA), Agree (A), Don't know (DK), Disagree (D), and Strongly Disagree (SD). All these scales had balanced questions for negatives and positives. 
http://dx.doi.org/10.4314/ajid.v7i2.4

\section{Results}

There were two hundred and twenty (220) school girls that completed the questionnaires. This gives a response rate of 97.8\%. Table 1 shows socio-demographic characteristics of the study population: $67.9 \%$ (150) students were orphans and $32.1 \%$ (70) were non-orphans. Also14\% were aged 12-13years; 55.7\% aged 14-15years and 30.3\% aged 16 years and above. Most orphans were Christians (71.0\%).

Less than $5 \%$ of both orphaned and non-orphaned girls said they came from rich families. Slightly over half $(53 \%)$ of the orphaned girls compared to $39 \%$ of the non-orphaned girls were from poor families. Just less than half (46\%) of the orphans and more than half of the non-orphaned girls said they were from average income families.

Table 2 presents data on the causes of orphan-hood: Overall, 30.0\% had lost a mother, $43.5 \%$ lost a father, and $26.7 \%$ both parents. Most parents for AIDS orphans occurred about 1990-1999 and this was statistically significant ( $<<0.05$ ). Most AIDS orphans live with their close relatives $(65.3 \%)$ while for the others $(42.7 \%)$ with their mothers and this finding was statistically significant $(\mathrm{p}<0.05)$.

Table 2 further shows that (29.3\%) of the girls that were orphaned to HIV/AIDS had lost a father. The girls that were orphaned to other causes had lost their fathers mainly during the period 1980-1999 when Uganda was undergoing a series of political turmoil. More than half of the girls orphaned to HIV/AIDS (65.3\%) were staying with a close relative as opposed to nearly a quarter $(25.3 \%)$ of girls orphaned to other causes.

Table 1: Socio-economic characteristics of the respondents

\begin{tabular}{lcc}
\hline Characteristics & Orphans (\%) & Non-orphans (\%) \\
\hline Age group & $21(14.0 \%)$ & $10(14.3 \%)$ \\
$12-13$ & $82(55.0 \%)$ & $40(57.1 \%)$ \\
$14-15$ & $47(31.0 \%)$ & $20(28.6 \%)$ \\
16 and above & $\mathbf{1 5 0}(\mathbf{1 0 0 . 0 \% )}$ & $\mathbf{7 0}(\mathbf{1 0 0 . 0} \%)$ \\
Total & & \\
Religion & $22(15.0 \%)$ & $15(21.0 \%)$ \\
Muslim & $21(14.0 \%)$ & $08(11.0 \%)$ \\
Born again & $103(70.0 \%)$ & $50(69.0 \%)$ \\
Christians & $02(1.0 \%)$ & \\
Jehovah's witnesses & $\mathbf{1 4 8}(\mathbf{1 0 0 . 0 \% )}$ & $\mathbf{7 3 ( 1 0 0 . 0 \% )}$ \\
Total & $46(31.0 \%)$ & $21(29.0 \%)$ \\
Level of education & $49(33.0 \%)$ & $24(33.0 \%)$ \\
Senior One & $55(37.0 \%)$ & $27(38.0 \%)$ \\
Senior Two & $\mathbf{1 5 0}(\mathbf{1 0 0 . 0 \% )}$ & \\
Senior Three & $02(1.0 \%)$ & $02(3.0 \%)$ \\
Total & $74(53.0 \%)$ & $24(39.0 \%)$ \\
Reported economic status of their families & $35(57.0 \%)$ \\
Rich & $64(46.0 \%)$ & $61(100.0 \%)$ \\
Poor & $140(100.0 \%)$ & \\
Average &
\end{tabular}


Kitara et al., Afr. J. Infect. Dis. (2013) 7(2): 36 - 43

http://dx.doi.org/10.4314/ajid.v7i2.4

Table 2: Parental status of the orphans

Causes of orphan-hood

AIDS Orphans Non-AIDS Orphans $\quad \chi^{2} \quad$ Statistical test

\begin{tabular}{lllll}
\hline Variables & $\mathrm{n}=75$ & $\mathrm{n}=75$ & & \\
& & & & \\
Orphan type & Paternal & $30(40.0 \%)$ & $35(46.7 \%)$ & \\
& Maternal & $17(22.7 \%)$ & $28(37.3 \%)$ & $\mathrm{p}<0.05$ \\
Total & Both Parents & $28(37.3 \%)$ & $12(16.0 \%)$ & \\
Year of parent's & $1980-1989$ & $\mathbf{7 5}(\mathbf{1 0 0 . 0 \% )}$ & $\mathbf{7 5 ( 1 0 0 . 0 \% )}$ & \\
Death & $1990-1999$ & $44(58.7 \%)$ & $26(34.7 \%)$ & \\
& 2000 and above & $19(25.3 \%)$ & $17(22.6 \%)$ & $\mathrm{p}<0.05$ \\
Total & & $\mathbf{7 5}(\mathbf{1 0 0 . 0 \% )}$ & $\mathbf{7 5}(\mathbf{1 0 0 . 0 \% )}$ & \\
Present Guardian & Close relative & $49(65.3 \%)$ & $19(25.3 \%)$ & \\
& Distant relative & $26(34.7 \%)$ & $10(13.3 \%)$ & $\mathrm{p}<0.05$ \\
& Mother & - & $32(42.7 \%)$ & \\
& Father & - & $14(18.7 \%)$ & \\
\hline
\end{tabular}

Table 3: ANOVA results for Assertiveness and attitude towards education for the students

\begin{tabular}{lccccccc}
\hline Type of Respondent & \multicolumn{3}{c}{ Attitudes } & \multicolumn{3}{c}{ Assertiveness } \\
& Mean & $\mathrm{n}$ & $\mathrm{SD}$ & Mean & $\mathrm{n}$ & $\mathrm{SD}$ \\
\hline & & & & & & & \\
Orphans by HIV/AIDS & 3.77 & 56 & 0.50 & 1.61 & 66 & 0.16 \\
Orphans by other causes & 3.92 & 58 & 0.47 & 1.62 & 63 & 0.15 \\
Non-orphans & 3.98 & 60 & 0.38 & 1.68 & 69 & 0.13 \\
df & 173.00 & & & 197.00 & & \\
F value & 3.14 & \multicolumn{4}{c}{5.09} \\
Sig & $0.05^{*}$ & \multicolumn{4}{c}{$0.01^{*}$} \\
\hline
\end{tabular}

$* \mathrm{p}<0.05$

Key $\mathrm{n}=$ Number of Respondents, $\mathrm{SD}=$ Standard Deviation, $\mathrm{Sig}=$ Significance, $\mathrm{df}=$ Degrees of freedom.

From Table 3, Non-orphan school girls had the highest level of assertiveness (mean $=1.68, S D+0.13)$ than the others. Girls orphaned by HIV/AIDS had a lower assertiveness (mean=1.61, $\mathrm{SD} \pm 0.16$ ) than those orphaned because of other causes (mean=1.62, $\mathrm{SD} \pm 0.15$ ). Non-Orphan secondary school girls had a more positive attitude towards education (mean=3.98, $\mathrm{SD} \pm 0.38)$ than the orphaned groups of girls. Among the orphans, those orphaned by HIV/AIDS had the least attitude towards education (mean=3.77, $\mathrm{SD} \pm 0.50$ ) compared to those by other causes (mean=3.92, $\mathrm{SD} \pm 0.47$ ). The results show that orphans due to HIV/AIDS had lower assertiveness and attitude to education compared to orphans by other causes and non-orphans.

Table 4: T-test results for Assertiveness and attitude towards education for orphaned and non-orphaned adolescent school girls

\begin{tabular}{llrrrrr} 
Variable & Type of Respondent & $\mathbf{n}$ & mean & t & df & Sig (2 tailed) \\
\hline Assertiveness & Orphan & 130 & 1.62 & -3.11 & 196 & 0.00 \\
& Non-orphan & 68 & 1.68 & -3.27 & & \\
Attitude towards peers & Orphan & 142 & 3.83 & -1.68 & 207 & 0.10 \\
& Non-orphan & 67 & 3.98 & -1.81 & & \\
Attitude towards class Subjects & Orphan & 137 & 3.73 & -0.07 & 205 & 0.95 \\
& Non Orphan & 70 & 3.74 & -0.07 & & \\
Attitude towards teachers & Orphan & 137 & 3.94 & -0.33 & 205 & 0.74 \\
& Non-Orphan & 70 & 3.96 & -0.33 & & \\
Attitude towards school facilities & Orphan & 142 & 3.47 & -3.13 & 210 & 0.00 \\
\hline
\end{tabular}




\section{http://dx.doi.org/10.4314/ajid.v7i2.4}

Table 4 shows that in all the variables the means of the non-orphaned girls were higher than those of the orphaned girls. The non-orphaned highest mean score was in the attitude toward peers (mean=3.98) and the lowest in assertiveness $($ mean $=1.68)$. The orphaned girls highest mean score was in attitude towards teachers (mean=3.94) and the lowest in assertiveness $($ mean $=1.62)$. In both orphaned and non-orphaned categories, assertiveness of the girls was rather low.

The results above confirm the statistical significance of attitude to school facilities $(\mathrm{p}=0.00)$ and assertiveness $(\mathrm{p}=0.00)$ with a ttest. The breakdown of the attitude scale into sub-components showed that attitude towards school facilities had a positive significance $(\mathrm{p}=0.00)$ in the whole attitude scale. The rest of the sub-components were not statistically significant.

Table 5: Pearson correlations between assertiveness and attitude towards education of orphaned adolescent school girls

\begin{tabular}{lll}
\hline Variables & & Assertiveness \\
\hline Attitude & $\mathrm{r}$ & 0.47 \\
& $\mathrm{p}$ & $0.00^{* *}$ \\
& $\mathrm{n}$ & 104 \\
\hline
\end{tabular}

$* *=$ significant at $\mathrm{p}<0.01$

Table 5 indicates that attitude towards education was positively correlated with the level of assertiveness $(r=0.47, p=0.00)$. This means that attitude towards education was affected by the level of assertiveness in orphaned girl.

Table 6: Pearson Correlation results between Assertiveness and components of attitude towards education for orphaned adolescent school girls

\begin{tabular}{llll}
\hline Sub components of the attitude scale & Assertiveness & \\
& $\mathrm{r}$ & $\mathrm{P}$ & $\mathrm{n}$ \\
\hline Attitude towards peers & $0.36^{* *}$ & 0.00 & 124 \\
Attitude towards class subjects & $0.37^{* *}$ & 0.00 & 120 \\
Attitude towards teachers & $0.43^{* *}$ & 0.00 & 122 \\
Attitude towards school facilities & $0.16^{*}$ & 0.04 & 123 \\
\hline
\end{tabular}

$* \mathrm{P}<0.05 * * \mathrm{p}<0.01$

Table 6 indicates that all the sub-sections of the attitude scale had a positive correlation with assertiveness: $(r=0.36, p=0.00)$ for attitude towards peers; $(r=0.37, p=0.00)$ for class subjects; $(r=0.43, p=0.00)$ towards teachers; and $(r=0.16, p=0.04)$ for school facilities. The difference in the p-value for attitude towards schools shows that this sub-section had a higher positive correlation with the other variables than the other sub sections on the attitude scale.

\section{Discussion}

Most orphaned girls were from poor families while the majority of the non-orphaned girls were from average income families. This situation was confirmed by the Head teachers who acknowledged that, because of many poor orphans in their schools, it was becoming increasingly difficult to run their schools. Government had ceased its contribution of school fees to orphans. Only orphans aided by Non- Governmental Organizations (NGOs), Good Samaritans and charitable organizations had paid the school fees of children they were sponsoring in those schools. The poor background of the orphans had a negative effect on assertiveness and attitudes of school girls towards education. Most girls orphaned to HIV/AIDS stayed with their close relatives as opposed to those orphaned by other causes.

Female headed families were the most commonly encountered among these orphaned adolescent school girls. This could have made it difficult for adolescents' girls who needed the presence of a father in building their self-esteem and assertiveness and to acquire those characteristics. Moreover, female headed households were known to experience higher poverty levels since females were often less educated and may have not had a well paying job (Uganda Bureau of Statistics, 2006). The type of relationship that existed in the student's life had an effect on their assertiveness and attitude towards education. When our data was subjected to a $\chi^{2}$ Statistical analysis, it revealed a statistically significant difference in the numbers for the orphan type, the year of death and the current guardian. This is however at variance with what Svanberg (1998) found; He noted that the loss of a mother was more detrimental to the later development of a child.

The majority of the parents of HIV/AIDS orphaned girls died during 1990-1999, perhaps as a result of infections that occurred in the 1980s when the HIV/AIDS awareness levels was very low in this country. It had been reported that at the time (80s), HIV/AIDS prevalence stood at close to 30\% (Uganda AIDS Commission, 2000). The majority of the girls orphaned to HIV/AIDS were staying with a close relative, a factor which could have provided the required family and social support to the orphaned girls. However, our studies found out that HIV/AIDS orphans in particular were unable to afford the basic necessities of life and school fees. This supported the finding by Price and Cioci (1993) that the erosion of familial and social supports complicated the lives of these adolescents. Foster (2000) also found that family safety nets were weakened as a result of orphan hood resulting from HIV/AIDS. 


\section{http://dx.doi.org/10.4314/ajid.v7i2.4}

The study found that non-orphans were more assertive and had a more positive attitude towards education. Girls orphaned by other causes had higher assertiveness to girls orphaned to HIV/AIDS and more positive attitude towards education. Girls orphaned to HIV/AIDS were the least assertive and their attitude towards education was most negative. This finding supported Denscombe (2000) who established that orphan hood due to HIV/AIDS and other causes stressed up students. Van Heerden (1999) found out that discrimination by categorization of girls influenced their levels of assertiveness and attitude towards education. The girls in racist schools needed higher levels of self-esteem and assertiveness to cope in the schools and perform well (Van Heerden, 1999). The same situation perhaps applies to the discrimination and stigmatization being experienced by HIV/AIDS orphans girls in secondary schools in Kampala.

From the study, assertiveness of HIV/AIDS orphans was lower than that of orphans by other causes. Uganda is a country that puts a lot of human and financial resources in sensitizing the public about the need to overcome the AIDS stigma (Nalwanga, 1998; Tusabe, 1998). Historically, Uganda was known internationally for having tackled the problem of HIV/AIDS with utmost openness (Nalwanga, 1998; Tusingwire, 1996). Unfortunately this was not followed up with training on assertiveness to enable HIV/AIDS orphans cope. Although people affected by HIV/AIDS were accepted by the public, observation showed that in individual communities, HIV/AIDS stigmatization was still quite High (Nalwanga, 1998; Baguma, 1997; Kitara et al, 2011). This was very clear in some schools where girls did not want to be identified as HIV/AIDS orphans.

Girls orphaned by AIDS had the lowest level of assertiveness. Both orphans by AIDS and orphans by other causes were less assertive than the non-orphaned girls. This was not very surprising when one considered the socio-economic status of the girls. These findings concurred with Berk, (1997) who reported that transitions such as family disruption made adolescents at greatest risk for academic and emotional difficulties. Where a young parent was widowed, adolescents were left lonely, isolated and depressed affecting their levels of self-esteem and assertiveness (Price \& Cioci, 1993). This was the reason why the assertiveness levels of orphans, especially orphans by HIV/AIDS were low.

The study found that in Uganda, it was common to see relatives of orphans take over all the assets of the orphans, and the children, especially girls, needed to learn to be assertive and to be protected. Where there was stigmatization as in the case with orphans by HIV/AIDS, not just self-esteem but, assertiveness, were needed to help the girls get on with their educational life. Assertiveness was needed for the achievement of aspirations and healthy social interactions. Although all girls needed to improve their levels of assertiveness, the need was greater among orphans and especially those orphaned to HIV/AIDS.

Assertiveness was slightly more positively correlated with attitude towards education. Thus, the higher the level of assertiveness, the more positive a girl would be in her attitude towards education. Attitude towards school facilities was more significant than attitude towards peers, class subjects and teachers. Thus, the presence of a well stocked library, good food, working space in the classroom and a fence for security were very positively and significant to the level of assertiveness in the girls. These facilities placed a girl in a position where she was well informed, physically developed and less vulnerable so that she was able to assert herself. This too led her to have a more positive attitude towards education.

The findings of this study were in agreement with those of Ungar, (2000) who contended that association with peers promoted identities that challenged the stigmatizing labels to girls, and this was in line with the findings of this study. The study generally found a positive and a statistically significant relationship between assertiveness and attitude towards teachers. Gruskin and Tarantola, (1999) noted the need to ensure that children are no longer objects of decisions affecting them but subjects taking part in these decisions and therefore, this could only happen if they were assertive. These decisions and sticking by them could only be academic, professional or personal (Gruskin and Tarantola, 1999). Gage, (1997) also earlier reported that problems of stereotyping, lack of balance of power, scarcity of information and services, broken networks and lack of responsibility by schools made the girls less assertive. Assertiveness was, therefore, a prerequisite if girls were to have a positive attitude towards education (Gage, 1997). The non-orphan girls had the highest level of assertiveness.

From the study, stigma associated with HIV/AIDS made the girls to have a low level of assertiveness and were not so positive attitude towards education. This was in line with the findings of Midgley, Arunkumar and Urdan (1996) who reported that students use academic self-handicapping as a mechanism by which negative attitudes become translated into behaviours that influenced performance outcomes. In the current study, orphans by other causes had low levels of assertiveness and a lower attitude towards education lower than that of the non-orphans. Orphans due to AIDS had the lowest levels of both assertiveness and attitude towards education. Most likely, the orphan girls used orphan-hood as a self-handicapping mechanism to negatively affect their attitude towards education.

Furthermore, the study revealed that more orphans had lost a father than a mother, and this implied that more orphans were being raised by their mothers or relatives. The levels of assertiveness and attitude of orphans towards education were, thus, largely influenced by the presence of a mother or relative. This was in line with Wahl and Blackhust (2000) who observed that children were strongly influenced by their mothers when it came to occupational aspirations. The lack of this influence adversely affected the child's aspirations (Wahl and Blackhust, 2000). Girls particularly needed a father-figure during adolescence (Wahl and Blackhust, 2000). But when it came to career development, shaped by attitude towards education, the mother's role could be significant (Wahl and Blackhust, 2000). This research finding, thus, underscored the importance of assertiveness in enhancing a positive attitude towards education in all girls, but more so in orphan girls, and especially orphans to HIV/AIDS.

The authors would wish to state that the study may have had some limitations in that it was conducted in an urban center (capital city) and therefore the findings may be thought not to be applicable to the rural schools in the countryside of Uganda. However, the authors wish to inform the readers that over $70 \%$ of the students studied were from the countryside of Uganda and therefore the study findings remain relevant and applicable to all communities in the country. 
http://dx.doi.org/10.4314/ajid.v7i2.4

\section{Conclusion}

Non-orphaned girls have a higher level of assertiveness than orphaned girls. Similarly, non-orphaned girls have a more positive attitude towards education compared to orphaned girls.

\section{Recommendation}

Girls orphaned to HIV/AIDS should be supported to gain their assertive in order to improve their attitudes towards education. This could be achieved by developing a school curriculum that supports and encourages HIV/AIDS orphan girls to gain their assertiveness and maintain a positive attitude towards education.

\section{Acknowledgements}

The authors are very grateful to the six secondary school girls who willingly accepted to provide this information for our research. The support from the school of Education, Makerere University and the cooperation of the research assistants is recognized.

Competing interest: Authors declare no competing interests.

\section{References}

1. Baggaley RC, Needham D (1997). Africa's emerging AIDS-orphans crisis. CMAJ: Canadian Med Assoc J; 156 (6): 873-875.

2. Baguma P (1997). Traditional Healing As a Coping Reaction to AIDS Pandemic in Uganda: AIDS from an Attribution Perspective. PhD Thesis, Makerere Univers. Libr, Kampala, Uganda.

3. Baguma P, Muhanguzi, FK (2000). Gender inequalities in education, Education policy and Budget. In Mukama R. (Ed.); The Gender Budget 1998/99. Published by Forum for Women in Democracy (FOWODE) Kampala, Uganda.

4. Berk LE (1997). Child Development. Allyn and Bacon, Boston, USA.

5. Denscombe M (2000). Social Conditions for Stress: Young people's experience of doing GCSEs. Br Educational Research J, 26 (3): 359-374.

6. Foster G (2000). The capacity of the extended family safety net for orphans in Africa. Psychology, Health \& Medicine; 5 (1): 55-62.

7. Gage A (1997). Female Empowerment and Adolescent demographic behaviour. Pennsylvania State University, USA.

8. Gruskin S, Tarantola D (1999). Abstract 44/43: Children Confronting HIV/AIDS: The convergence of Rights and Prevention and Care needs. Geneva 98: Abstract on legal Ethical and Human Rights Issues. Boston MA. USA.

9. Guez W, Allen J (Eds.1998). Module 4, Behaviour Modification, Uganda. United Nations Education and Science Organisation(UNESCO).

10. Gunther M, Crendles S (1998). A place called HOPE: Group Psychotherapy for adolescents of parents with HIV/AIDS. Child Welfare; 77 (2): 251-271.

11. Kee-Lee C (2000). Intimacy and psychosocial adjustment in Hong Kong Chinese adolescents. J Genetic Psychol; 141151.

12. Kitara DL, Bwangamoi PO, Odong P, Acullu D, Odongo-Aginya E (2011). HIV/AIDS stigmatization against the youths in Gulu, Northern Uganda: A major drawback in fight against the spread of HIV/AIDS. J Med. Med Sci. 2(4):805-811.

13. Midgley C, Arunkumar R, Urdan TC (1996). "If I Don't Do well Tomorrow, There's a reason": Predictors of Adolescents' Use of Academic Self - Handicapping Strategies. J Educat Psychol; 88(3): 423- 434.

14. Nalwanga S (1998). Factors affecting HIV/AIDS related knowledge, attitudes and behaviours among men and women of Central Uganda: A comparative study. MA thesis, Institute of Statistics and Applied Economics, Makerere Univers. Libr. Kampala, Uganda.

15. Opolot JA, Cele CI, Jehopio PJ, Okurut HE, Okello JP, Rutondoki EN, Kabatereine GP, Nakkazi DR, Udongo BP (1997). The Level of Life Skills of Uganda's Secondary School Students. A Baseline Study Report. Ministry of Education and Sports for UNICEF, Kampala, Uganda.

16. Price RH, Cioci M (1993). Webs of influence; School and Community programmes that enhance adolescent health and education. Teachers College Record; 94 (3). 487-521.

17. Svanberg POG (1998). Attachment, resilience and prevention. J Mental Health; 7 (6): 543-579.

18. Tusabe PB (1998). AIDS: Its socio-ethical implications: A case study of Uganda's situation. MA. thesis Makerere Univers. Libr, Kampala, Uganda.

19. Tusingwire H (1996). Factors influencing the spread of AIDS in Uganda. A secondary analysis using data from the sero-survey carried out by ACP in 1988-1989. M.A. thesis, Makerere Univers. Libr, Kampala, Uganda.

20. Uganda AIDS Commission (2000). Status of HIV/AIDS in Uganda. Uganda AIDS Commission Publication, Kampala, Uganda. 
Kitara et al., Afr. J. Infect. Dis. (2013) 7(2): 36 - 43

http://dx.doi.org/10.4314/ajid.v7i2.4

21. Uganda Bureau of Statistics (2006). Population and Housing Census-2006. Uganda Bureau of Statistics Publication, Ministry of Finance, Kampala, Uganda.

22. Ungar MT (2000). The Myth of Peer Pressure. Adolescence; 35 (137): 167-180.

23. Van Heerden ME (1999). My School, your school, our school? Issues of attitude, behaviour and identity among black and white pupils in desegregated South African high schools. South Afri J Ethnology; 22, 2.

24. Wahl KH, Blackhurst A (2000). Factors affecting the Occupational and Educational Aspirations of Children and Adolescents. Professional School Counseling; 3 (5): 367-374. 